Journal of Advanced Research in Fluid Mechanics and Thermal Sciences

Journal homepage: www.akademiabaru.com/arfmts.html ISSN: 2289-7879

\title{
Characteristic Curve Prediction of a Commercial Centrifugal Pump Operating as a Turbine Through Numerical Simulations
}

\author{
Diego Penagos-Vásquez ${ }^{1}$, Jonathan Graciano-Uribe ${ }^{1,}{ }^{*}$, Sebastián Vélez García ${ }^{1}$, Jorge Sierra del Rio ${ }^{2}$ \\ Faculty of Engineering, Department of Mechatronics and Electromechanics, Instituto Tecnológico Metropolitano, Robledo Campus, Calle 73 No. \\ 76A-354, Vía al Volador, Medellín, Colombia \\ 2 Faculty of Engineering, Department of Engineering, Environmental Research Group - GIIAM, Institución Universitaria Pascual Bravo, Robledo \\ Campus, Calle 73 No. 73A-226, Vía al Volador, Medellín, Colombia
}

\section{ARTICLE INFO}

Article history:

Received 11 December 2020

Received in revised form 22 April 2021

Accepted 23 April 2021

Available online 28 May 2021

\section{Keywords:}

Specific speed; Hydraulic profile; Centrifugal pump; Radial flow; Pump as Turbine; CFD

\section{ABSTRACT}

\section{Introduction}

As a response to population growth, the use of various types of energy is required to produce tangible elements and to carry out daily activities [1]. However, it is necessary to transform energy, through renewable or non-renewable sources, where the latter is limited in nature and causes environmental damage. That is why technological development has made possible to transform energy through sustainable sources [2]. Currently, emphasis is being placed on the production of clean energy, including renewable energy sources (RES), following the seventh objective of sustainable development: affordable and non-polluting energy [3]. Although RES generates low environmental impact, when assessing cost and efficiency, their value, in $[\mathrm{kW} / \mathrm{h}]$ is even higher than conventional energy sources [4]. On the other hand, International Renewable Energy Agency (IRENA) [5] remarked that the average global cost of available renewable energy decreased in 2018 compared to the previous year, and projected that by 2019 it would have the same trend, emphasizing that

\footnotetext{
* Corresponding author.

E-mail address: jonathangraciano@itm.edu.co
}

https://doi.org/10.37934/arfmts.83.1.153169 
hydraulic energy, the cost was reduced by $11 \%$. This opens the way for greater competitiveness and use of RES. Similarity, REN 21 [6] mentioned hydroelectric energy is characterized by its stability in the market and growing demand. In addition, the world growth of hydroelectric energy in 2018 was like previous year, increasing by $20 \mathrm{GW}$, for an installed capacity of $1132 \mathrm{GW}$. The pumped storage capacity increased by $1.9 \mathrm{GW}$, for a total of $160 \mathrm{GW}$, representing most of the energy storage of this type. The new pumped storage projects are being upgraded to produce a rapid response to changing electricity conditions. According to a report by the International Hydropower Association (IHA) [7], China is the largest water-based power producer, with a capacity of $341 \mathrm{GW}$, comprising $28.42 \%$ of global production. Colombia is ranked 20th, contributing $12 \mathrm{GW}$, incorporating $1 \%$ of world production, and is the third country in South America with the greatest capacity below Brazil with $100 \mathrm{GW}$ and Venezuela with $15 \mathrm{GW}$. According to Acolgen [8], Colombia has an installed capacity of $17203 \mathrm{MW}$, where $69.03 \%$ comes from hydraulic energy, equivalent to $11876 \mathrm{MW}$. However, distant regions from large cities do not have electricity generation plants, even though they have numerous water sources [9]. As a result, the non-interconnected areas must generate their own electricity. As a result, Colombia has not exploited all its capacity to generate energy and supply electricity to the most remote communities.

To solve this problem, there are different types of turbines for use in hydroelectric generation. However, they require a high flow rate and head of operation and a more complex infrastructure [10]. On the other hand, pump as turbine (PAT) generates similar power with a lower operating flow, making them a feasible option for small-scale hydroelectric generation [11]. This type of turbomachine is easy to acquire due to mass production, operates in wide flow and head ranges, has a long useful life, easy installation and high availability of spare parts [12-15]. PAT can be used with intermittent generation systems, such as wind and photovoltaic parks, because it stabilizes electricity if variations from other sources occur [16]. Shabani and Mahmoudimehr [17] studied the technoeconomic evaluation, integrating the photovoltaic system and pumped-storage hydroelectricity (PV/PSH), demonstrating that this system is better than storing photovoltaic energy in a battery and proving that PSH is not as expensive as battery storage. On the other hand, Nyeche and Diemuodeke [18] conducted a study on the economic feasibility of a hybrid plant. They concluded that the cost was $\$ 0.27 / \mathrm{kWh}$, being below the diesel generators, whose cost was $\$ 0.95 / \mathrm{kWh}$.

A centrifugal pump is a turbomachine that transforms the kinetic energy of a fluid into pressure energy, to lift a fluid to a site of greater height [19]. They are used in different sectors: water desalination, mining industry, petrochemical plants, and distribution of drinking water [20]. The characteristic curve of centrifugal pumps has been validated in literature, finding errors of $12 \%, 5$ $10 \%$ and $4 \%$, respect to efficiency [21-23]. In addition, the fluid dynamic behavior with pressure and velocity contours has been validated. The PAT concept refers to the inverse operation of a centrifugal pump, taking advantage of water energy and transforming it into rotational mechanical energy, to be coupled to an electric generator. The investment cost can be less than $50 \%$ compared to a conventional turbine, for powers below $50 \mathrm{~kW}$ [24]. Barbarelli et al., [25] experimentally studied 27 radial flow PAT, obtaining mathematical relations that predict its behavior. Also, the characteristic curve has been generated, showing that, as the pump flow increases, the head and the power generated increase, but the efficiency decreases [26,27]. Delgado et al., [28] found that the efficiency of the machine improves when working at variable speed. It has been validated the numerical and experimental model in axial flow pumps and mixed flow pumps [29-31]. Also, PAT has been proposed a methodology to use PAT instead of pressure relief valves, pressure fluctuation and vortex formation in the impeller [32-34]. On the other hand, when acquiring a commercial centrifugal pump, manufacturers do not give the characteristic curve in turbine mode. 
How could populations without access be supplied with electricity, using economic, sustainable, and non-polluting technology? The need to help regions that do not have electricity supply is necessary to improve the quality of life and to have access to technology. The main thing is based on economic and environmental framework, allowing to avoid the deterioration of the ecosystem and that it is sustainable in time. Therefore, the objective of the present work is to develop, by computational simulations, the characteristic curve of a radial flow pump operating as a turbine, to propose an adequate selection of this type of turbomachines for the supply of electric energy in populations that are not part of the national interconnected system. With this, the intention is to show a methodology for the selection of PATs and to apply an economic technology for the noninterconnected areas, since no method was found that is being applied for the correct selection of these turbomachines.

\section{Methodology}

The present work proposes a methodology to determine the characteristic curve of a centrifugal pump of radial flow in turbine mode, using mathematical models based on the state of the art and numerical simulations to determine its fluid dynamic behavior. Figure 1 shows the procedures used for the development of this research, which begins obtaining a characteristic curve provided by a manufacturer, it extracts the information from the best efficiency point (BEP). Subsequently, the geometry is modeled (control volume of the impeller and volute), then these volumes are discretized. Later, the boundary conditions are established, after running the simulation the results are analyzed, validating them with the characteristic curve given by the manufacturer. Once the numerical model is validated, a methodology is established to generate a numerical simulation in turbine mode, which establishes the characteristic curve in turbine mode of a radial centrifugal pump as a prominent result.

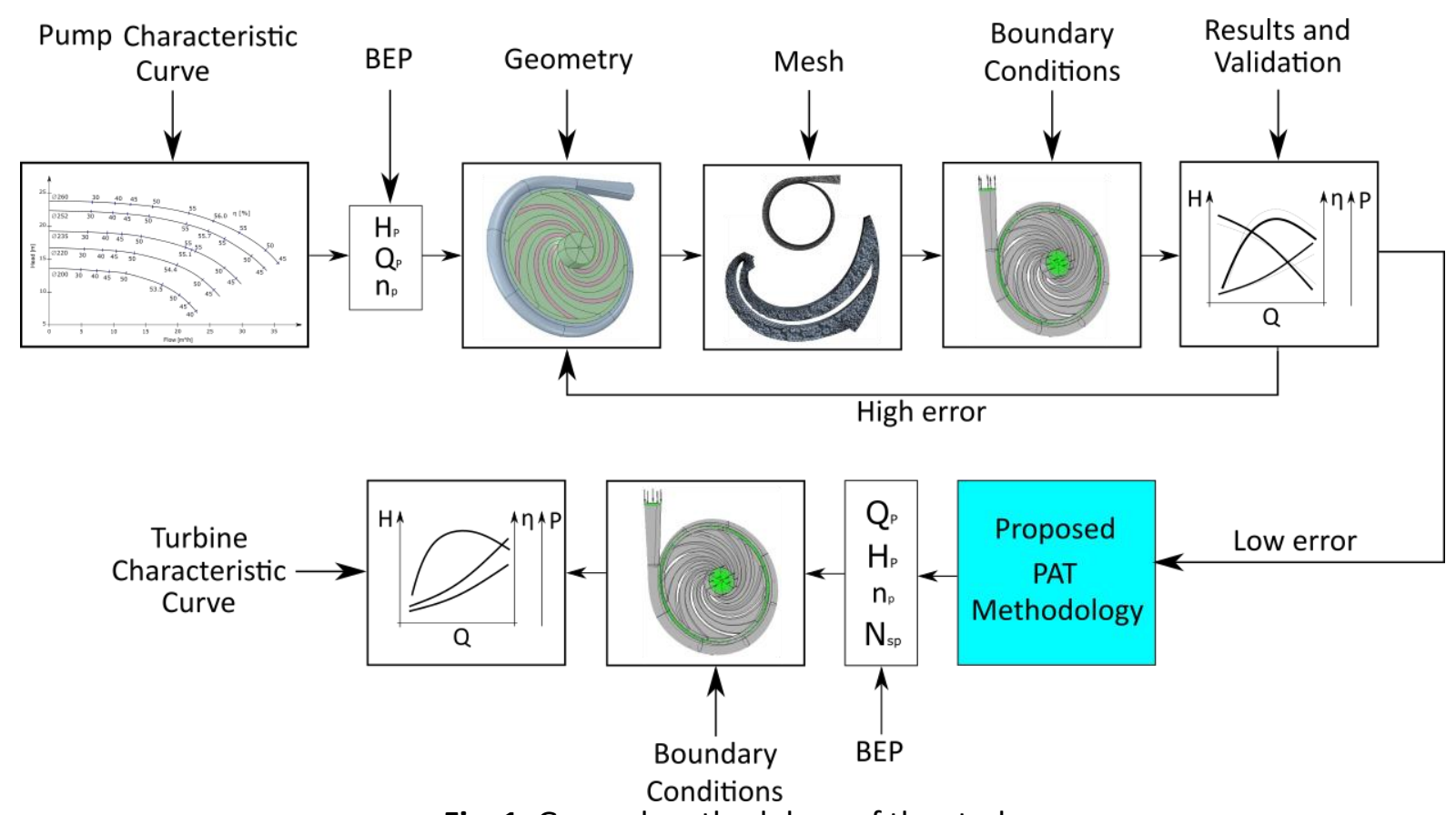

Fig. 1. General methodology of the study 


\subsection{Case Study}

The commercial centrifugal pump used for this analysis is the reference MegaCPK 065-040-250 of the manufacturer KSB [35]. The technical and BEP specifications are recorded in Table 1, where an impeller diameter of $260 \mathrm{~mm}$ and an efficiency of $56 \%$ are highlighted.

Table 1

Pump specifications at BEP

\begin{tabular}{ll}
\hline Concept & Detail \\
\hline Manufacturer & KSB \\
Reference & MegaCPK 065-040-250 \\
Flow Type & Radial \\
Suction Diameter [mm] & 65 \\
Discharge Diameter [mm] & 40 \\
Impeller Diameter [mm] & 260 \\
Blades & 6 \\
Flow $\left[\mathrm{m}^{3} / \mathrm{h}\right]$ & 25.49 \\
Head $[\mathrm{m}]$ & 20.71 \\
Rotational Speed [rpm] & 1450 \\
Efficiency [\%] & 56.0 \\
\hline
\end{tabular}

Figure 2 shows the digitized characteristic curve provided by the manufacturer. It shows a group of curves that differ respect to the impeller diameter. The red curve is used in this investigation, which has an impeller diameter of $260 \mathrm{~mm}$. The intersection lines (blue) represent the efficiency. Additionally, each point used in the numerical simulation is shown. On the right side, the scheme and the actual image of the pump is shown.
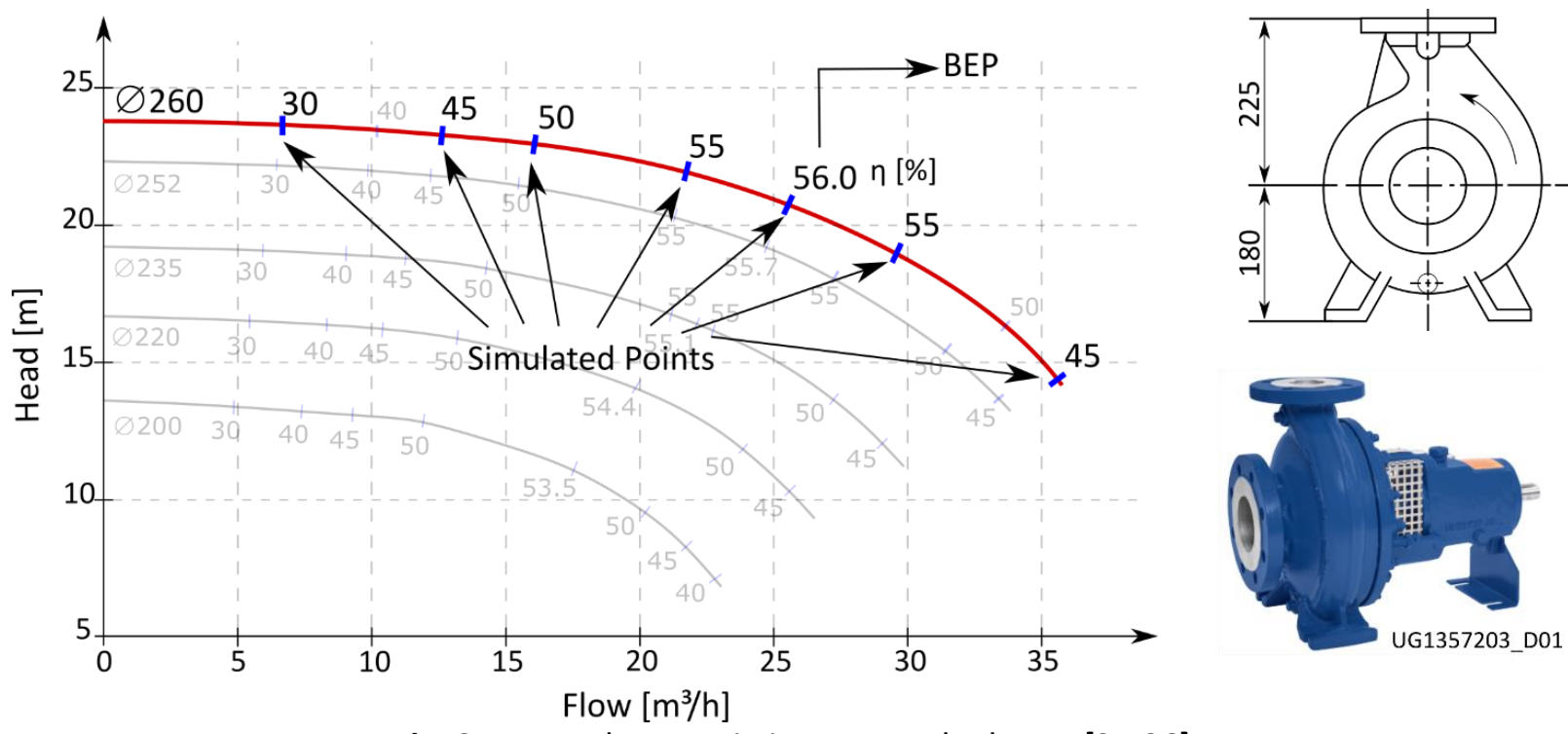

Fig. 2. Pump characteristic curve and scheme $[35,36]$

\subsection{Geometric Modeling and Control Volumes}

The computer modeling was done in the software Ansys 2019 R2. To generate the hydraulic profile, the Blade Design module was used, where BEP data, water density, rotational speed and number of blades are provided. With this, the software calculates the approximate control volume of impeller, volute, and blades section. Then, hydraulic profile is adjusted to ensure that the 
computer model is like real one. Figure 3 shows the result of the computer modeling. (a) exhibits the hydraulic profile obtained, showing the axis of rotation and direction of flow with black arrows. In (b), the impeller blades are displayed in an isometric view. In (c), the impeller control volume assembly and the volute are displayed, showing the fluid inlet and outlet. Finally, in (d) is evidenced by the slice view of the parameterized control volume, making a zoom to verify the alignment between the impeller and the volute.

(a)
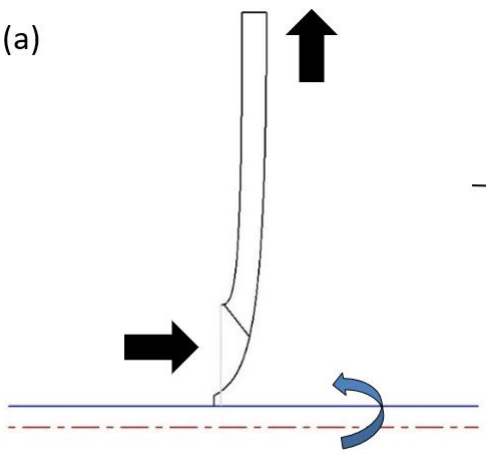

(c)

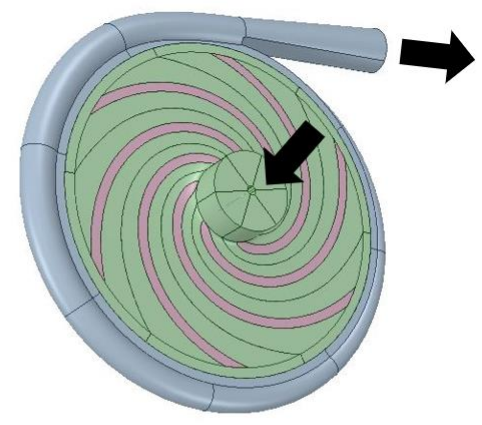

Flow direction (b)
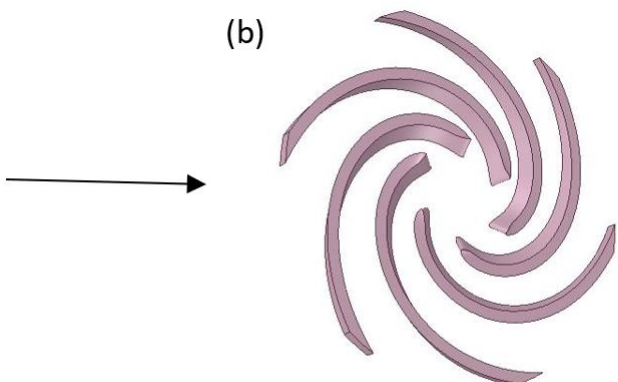

Rotation axis
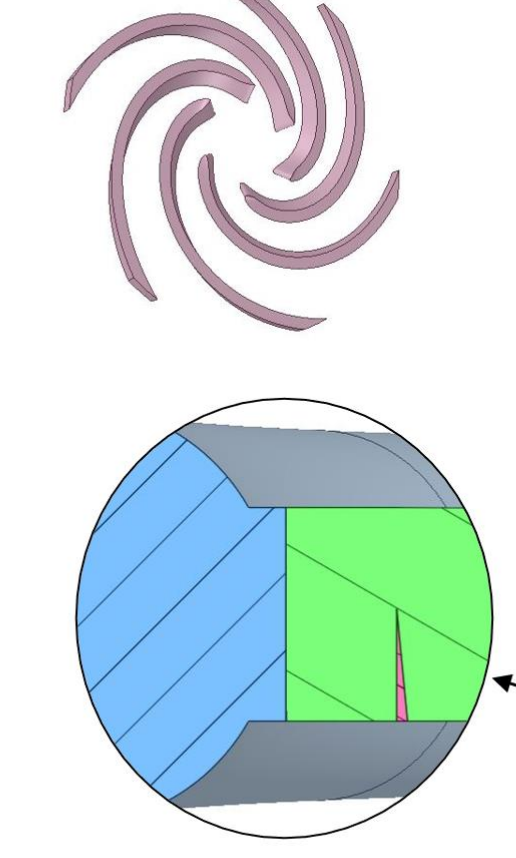

Volute Fluid (d)
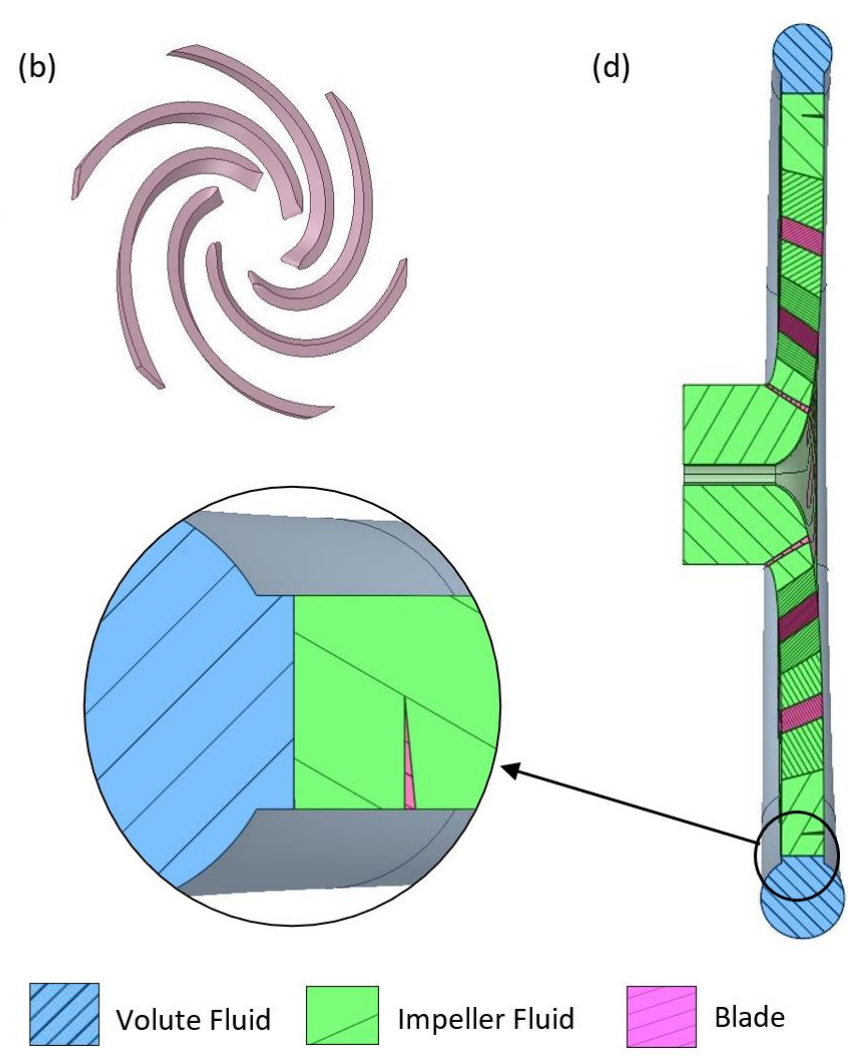

Impeller Fluid

Fig. 3. (a) Modeling of the hydraulic profile, (b) blades, (c) assembly and (d) aligned control volume

\subsection{Mesh}

Mesh was developed in the Meshing module of Ansys 2019 R2. A mesh independence study is carried out to guarantee the minimum number of elements that allow the approximation of the results for the experimental curve given by the manufacturer and optimal computational performance for the subsequent simulations. An appropriate number of elements is obtained when the control variable stabilizes rapidly with an error lower than $0.5 \%$ about the following refinement point [37-39]. Discretization is applied to the impeller and volute geometries, using different methods that allow the increase of elements without affecting the quality of the mesh [40].

BEP of the characteristic curve, presented in Table 1, is taken as a reference. Figure 4 shows the results of the mesh study. It can be observed a horizontal axis representing the variation of the mesh elements with respect to the vertical axes symbolizing the pump efficiency $\eta_{p}$ [\%], the error between the refined points $E_{p}[\%]$, and the head $H$ [m]. The pump efficiency is the reference parameter for the results because it relates the head variation to the power required by the turbomachine. On the other hand, three curves with decreasing trends are detailed, with a lower trend in the final section. As a result, it is determined that the minimum number of mesh elements is 1024849, which represents an error of $0.2 \%$ with respect to the following point. Additionally, the difference in efficiency with the most refined point ( 2314498 elements) is $0.3 \%$, which is not relevant when 
considering the high computational resource required. Finally, the change in head is not relevant from the minimum number of mesh elements determined, obtaining a difference of $0.1 \mathrm{~m}$.

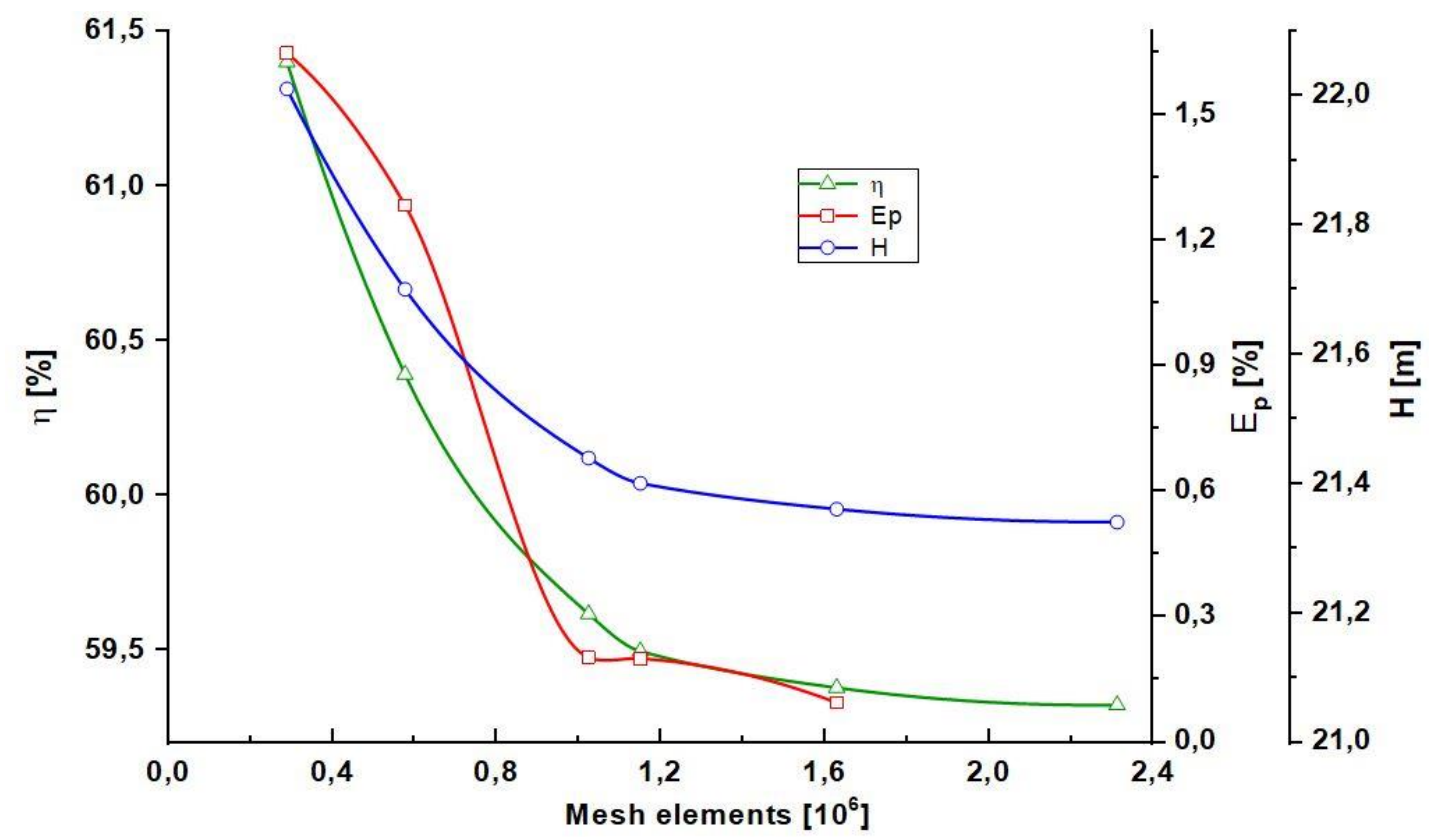

Fig. 4. Mesh independence study

Figure 5 shows the mesh for an impeller vane (a) and the volute (b), showing a cross-sectional view. Table 2 illustrates the mesh statistics and metrics. This last aspect is related to the minimum quality required by the Ansys-CFX software solver [40].

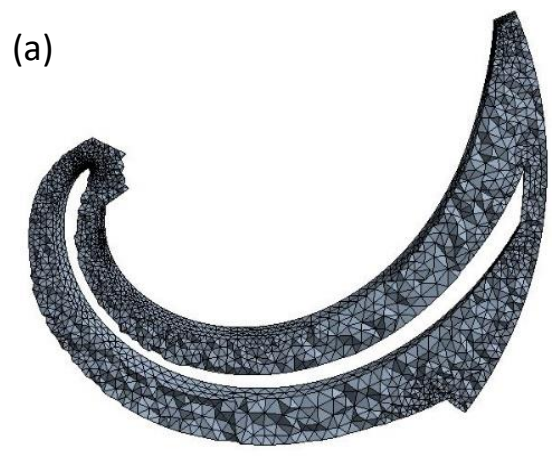

(b)

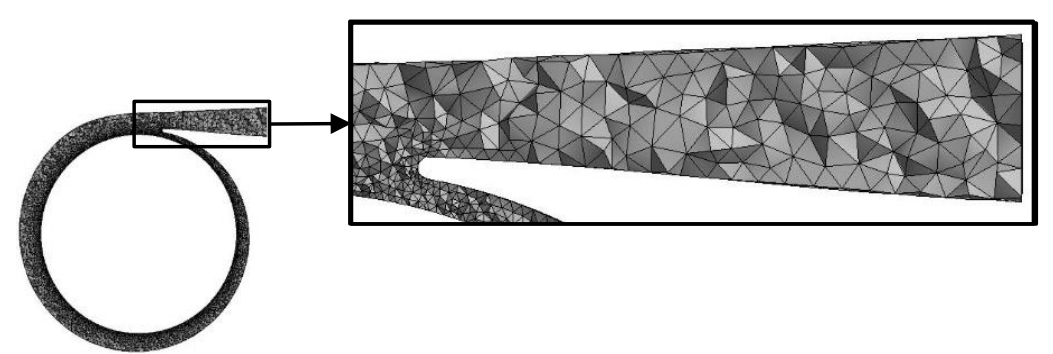

Fig. 5. (a) Discretion of the control volume of the impeller and (b) the volute

Table 2

Mesh statistics and metrics

\begin{tabular}{lllll}
\hline Elements & & & Metrics & \\
\hline Volume & Nodes & Elements & Concept & Value \\
\hline Impeller & 124104 & 601182 & Aspect Ratio & 10.725 \\
Volute & 84953 & 423667 & Expansion & 17 \\
Total & 209157 & 1024849 & Orthogonal Quality & 0.193 \\
\hline
\end{tabular}

\subsection{Governance Equations and Boundary Conditions}

The turbulence model used in this study is $k-\varepsilon$. This model solves two separate transport equations by considering the kinetic turbulent energy $k$ and dissipation $\varepsilon$ as unknowns. Additionally, 
it considers the average speed of the fluid in time [41]. Eq. (1)-(3) expresses the formulation of the stationary model $k-\varepsilon$ with its respective constants.

$$
\begin{aligned}
& \frac{\partial\left(\rho \mathrm{ku}_{\mathrm{i}}\right)}{\partial \mathrm{x}_{\mathrm{i}}}=\frac{\partial}{\partial \mathrm{x}_{\mathrm{j}}}\left[\left(\mu+\frac{\mu_{\mathrm{t}}}{\rho_{\mathrm{k}}}\right) \frac{\partial \mathrm{k}}{\partial \mathrm{x}_{\mathrm{j}}}\right]+\mathrm{P}_{\mathrm{k}}-\rho \varepsilon \\
& \frac{\partial\left(\rho \varepsilon \mathrm{u}_{\mathrm{i}}\right)}{\partial \mathrm{x}_{\mathrm{i}}}=\frac{\partial}{\partial \mathrm{x}_{\mathrm{j}}}\left[\left(\mu+\frac{\mu_{\mathrm{t}}}{\rho_{\varepsilon}}\right) \frac{\partial \varepsilon}{\partial \mathrm{x}_{\mathrm{j}}}\right]+\mathrm{C}_{1 \varepsilon} \frac{\varepsilon}{\mathrm{k}} \mathrm{P}_{\mathrm{k}}-\mathrm{C}_{2 \varepsilon} \rho \frac{\varepsilon^{2}}{\mathrm{k}} \\
& \mu_{\mathrm{t}}=\rho \mathrm{C}_{\mu} \frac{\mathrm{k}^{2}}{\varepsilon}=\frac{1}{2}\left(\frac{\partial \mathrm{u}_{\mathrm{j}}}{\partial \mathrm{x}_{\mathrm{i}}}+\frac{\partial \mathrm{u}_{\mathrm{i}}}{\partial \mathrm{x}_{\mathrm{j}}}\right)
\end{aligned}
$$

Eq. (4)-(6) defines turbulent kinetic energy and turbulent energy dissipation tensors, where the divergence operator is represented by the symbol $\nabla$ and $u$ is the fluid velocity vector. $A$ finite element procedure can be applied to solve the system of equations. The $k-\varepsilon$ turbulence model is used to predict the flow behavior in the mass regions [42].

$$
\begin{aligned}
& \rho(\mathrm{u} \cdot \nabla) \mathrm{u}=\nabla \cdot\left[-\mathrm{pI}+\left(\mu+\mu_{\mathrm{T}}\right)\left(\nabla \mathrm{u}+\nabla \mathrm{u}^{\mathrm{T}}\right)\right] \\
& \nabla \cdot \mathrm{u}=0 \\
& \rho(\mathbf{u} \cdot \nabla) \mathrm{k}=\nabla \cdot\left[\left(\mu+\frac{\mu_{\mathrm{t}}}{\rho_{\mathrm{k}}}\right) \nabla \mathrm{k}\right]+P_{k}-\rho \varepsilon \\
& \rho(\mathbf{u} \cdot \nabla) \varepsilon=\nabla \cdot\left[\left(\mu+\frac{\mu_{\mathrm{t}}}{\rho_{\varepsilon}}\right) \nabla \varepsilon\right]+\mathrm{C}_{1 \varepsilon} \frac{\varepsilon}{\mathrm{k}} \mathrm{P}_{\mathrm{k}}-\mathrm{C}_{2 \varepsilon} \rho \frac{\varepsilon^{2}}{\mathrm{k}}
\end{aligned}
$$

The turbulence model used in this research is $k-\varepsilon$. This model is considerably employed for its cost ratio, numerical results, and simulation efficiency, although it requires more mesh points and does not adequately capture the phenomena in the near-wall regions [43]. However, it is useful for freeshear layer flows with small pressure gradients, while for larger gradients the accuracy of the results is reduced [44].

However, several authors have used this model because of the approximation with the experimental results. Using the efficiency parameter, errors of $6 \%, 12 \%, 5-10 \%, 4 \%, 4 \%, 10 \%$ have been evidenced, so using this model in centrifugal pumps is acceptable $[19,21-23,29,45]$.

Two domains are configured: static for the volute and rotational for the control volume surrounding the blades. The type of analysis is stationary. Relative pressure is selected as input variable, set at $0 \mathrm{kPa}$. The output variable is mass flow, about the points on the characteristic curve. The density of water is $997.1 \mathrm{~kg} / \mathrm{m}^{3}$, considering an isothermal process [46]. The rotational speed of the impeller is $1450 \mathrm{rpm}$. The interface is Frozen Rotor, used for rotating turbomachines. The residual value is $1 \mathrm{E}-04$ and 1000 iterations, although it is usually relative, because it is necessary that there is convergence with the control variable, otherwise the geometry or mesh parameters must be modified.

To build the characteristic curve, the Eq. (7) and Eq. (8) are set in the software. Using Eq. (7), the head $\mathrm{H}[\mathrm{m}]$ is determined in both modes of operation, relating the output pressure $P_{\text {outlet }}[\mathrm{Pa}]$ and input $P_{\text {inlet }}[\mathrm{Pa}]$ of the flow respect to the density $\rho\left[\mathrm{kg} / \mathrm{m}^{3}\right]$ and the gravity $g\left[\mathrm{~m} / \mathrm{s}^{2}\right][42,47]$. Eq. (8) is used to calculate the efficiency in turbine mode $\eta_{t}[\%]$, by relating the power on the axis $P$ [kW] with the density, gravity, head, and flow $Q\left[\mathrm{~m}^{3} / \mathrm{s}\right][42,48,49]$. 
$H=\frac{P_{\text {outlet }}-P_{\text {inlet }}}{\rho g}$

$\eta_{t}=\frac{P}{\rho g H Q}$

\subsection{PAT Methodology}

The simulation in pump mode is carried out to proceed with the analysis in turbine mode, with the least possible error. By concatenating the points simulated in pump mode, the numerical simulation in turbine mode is realized. Through experimental analysis and review of the state of the art, it has been possible to predict the specific speed in turbine mode $N_{s t}$. This is achieved through analysis of different pumps, obtaining the trend graph, and relating variables such as flow, head, and efficiency in new curves. Table 3 summarizes the correlation obtained by authors who have investigated the subject, where the equation is identified, the range of the PATs specific speed analyzed and the number of experiments or reviews [24].

\section{Table 3}

Prediction $\boldsymbol{N}_{\text {st }}$

\begin{tabular}{lllll}
\hline Year & Author [Ref] & $\mathrm{N}_{\mathrm{sp}}-\mathrm{N}_{\mathrm{st}}$ correlation & $\mathrm{N}_{\mathrm{sp}}$ range & Detail \\
\hline 2019 & Rossi et al., [49] & $1.1048 \mathrm{~N}_{\mathrm{st}}$ & $5.0-80.0$ & 59 reviews \\
2018 & Barbarelli et al., [50] & $0.9867 \mathrm{~N}_{\mathrm{st}}+5.2818$ & $9.0-64.0$ & 27 experiments \\
2019 & Stefanizzi et al., [32] & $1.0826 \mathrm{~N}_{\mathrm{st}}+2.6588$ & $9.0-80.0$ & 27 reviews \\
2016 & Tan and Engeda [51] & $1.3297 \mathrm{~N}_{\mathrm{st}}-0.0883$ & $30.7-80.0$ & 4 experiments \\
2012 & Yang et al., [19] & $1.1250 \mathrm{~N}_{\mathrm{st}}+1.7300$ & $5.0-80.0$ & 55 reviews \\
2010 & Singh and Nestmann [52] & $1.0638 \mathrm{~N}_{\mathrm{st}}+3.3191$ & $14.6-79.1$ & 9 experiments, 4 reviews \\
2008 & Derakhshan and Nourbakhsh [53] & $0.3705 \mathrm{~N}_{\mathrm{st}}+5.0830$ & $14.6-55.6$ & 4 experiments, 7 reviews \\
\hline
\end{tabular}

Respect to named authors, the experimental work developed by Barbarelli et al., [50] is cited. This author characterized a total of 27 pumps, through analysis in a laboratory at the University of Calabria, Italy. However, the author started from the characterization in turbine mode, where he found mathematical correlations that allowed him to find the approximate site conditions in pump mode, with an approximate error of $15 \%$ and $20 \%$ for the flow rate and head, respectively. In this work it is proposed to use the inverse methodology proposed by the author, starting from the pump mode to find the site conditions in turbine mode. Figure 6 outlines the steps of the proposed methodology to find the PAT BEP conditions, starting from the pump characteristic curve. With this, we seek to use an existing methodology and offer an alternative for PAT selection site conditions. 


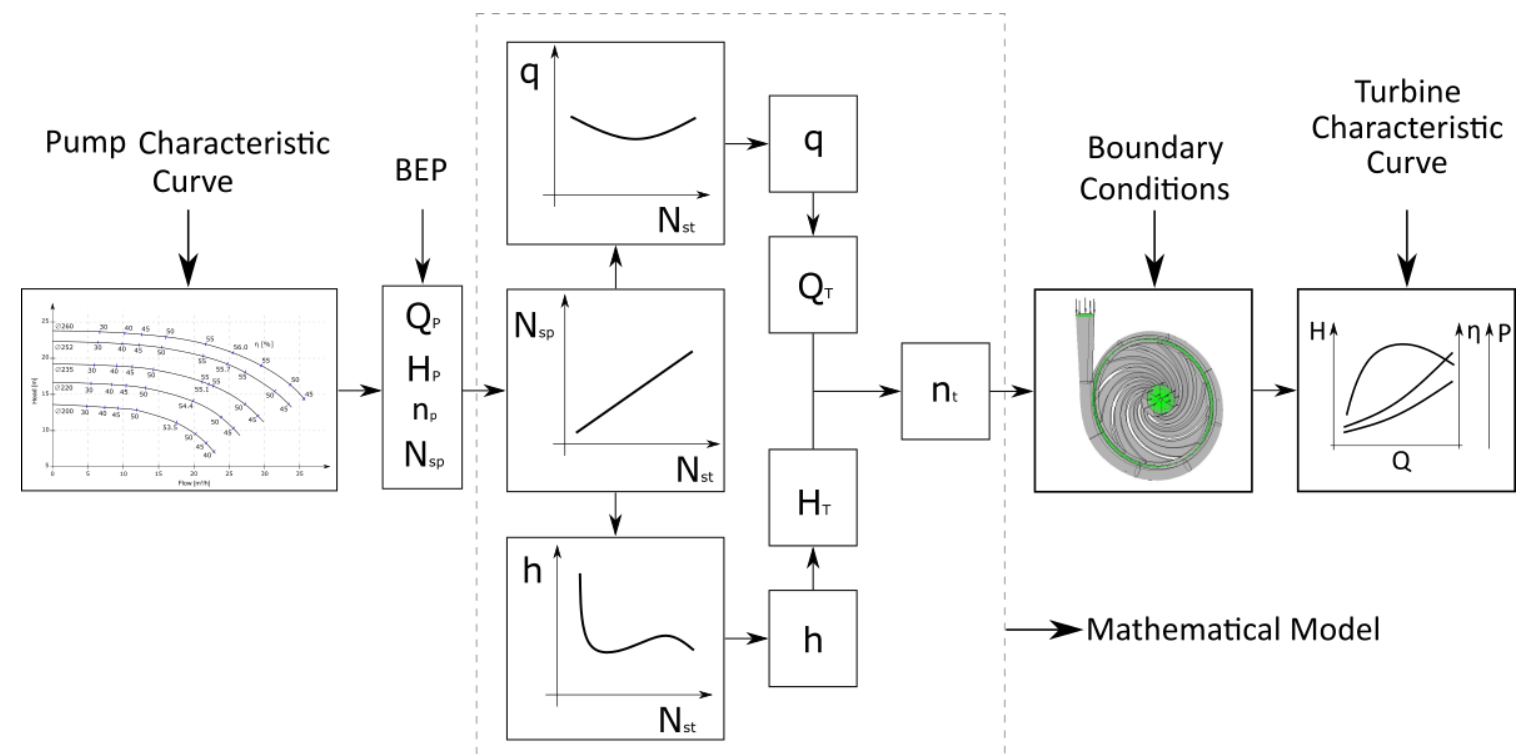

Fig. 6. Proposed methodology for radial flow PAT characterization

The mathematical model used to determine the site conditions starts from the pump mode. Sequentially, Eq. (9) is applied to obtain the head $H_{P}$ [m], flow $Q_{P}\left[\mathrm{~m}^{3} / \mathrm{s}\right]$ and the angular speed $n_{p}$ [rpm] of BEP and they are related to the specific speed in pump mode $N_{s p}$, which varies between 10 and 80 for the radial flow $[55,56]$. Eq. (10)-(12) presents the specific speed in turbine mode $N_{s t}$ and coefficients of flow $q$ and head $h$, obtained through experimental correlations [51]. Eq. (13) and Eq. (14) relate the flow and head coefficients with their analogues, where are obtained the site conditions $Q_{T}$ and $H_{T}$, respectively [51]. Finally, using Eq. (15) it is obtained the angular velocity $n_{t}$ when relating the specific velocity of the PAT [55]. Particularly, both specific speeds are related in a linear way, although in turbine mode is slightly lower [57]. On the other hand, the specific speed has dimensions of [rpm m3/4 s-1/2], but it is assumed dimensionless for simplicity $[25,54,58]$.

$$
\begin{aligned}
& N_{s p}=n_{p} Q_{P}^{0.5} H_{P}^{-0.75} \\
& N_{s t}=\frac{N_{s p}-5.2818}{0.9867} \\
& q=0.00026 N_{s t}^{2}-0.02302 N_{s t}+1.88171 \\
& h=-0.00003 N_{s t}^{3}+0.00331 N_{s t}^{2}-0.15047 N_{s t}+3.68497 \\
& Q_{T}=q Q_{P} \\
& H_{T}=h H_{P} \\
& n_{t}=N_{s t} H_{T}^{0.75} Q_{T}^{-0.5}
\end{aligned}
$$

Table 4 summarizes the values calculated respect to the pump analyzed, by means of Eq. (9)-(15). The objective is to find the site conditions and the rotational speed of the impeller, to parameterize the simulation. 
Table 4

Calculated variables

\begin{tabular}{lll}
\hline Symbol & Variable & Value \\
\hline$N_{s p}$ & Specific speed in pump mode [-] & 12.57 \\
$N_{s t}$ & Specific speed in pump mode [-] & 7.38 \\
$q$ & Flow coefficient [-] & 1.73 \\
$h$ & Head coefficient [-] & 2.74 \\
$Q_{T}$ & Site flow [m $3 / \mathrm{h}]$ & 43.99 \\
$H_{T}$ & Head site [m] & 56.79 \\
$n_{t}$ & Rotational speed [rpm] & 1382 \\
\hline
\end{tabular}

Boundary conditions in turbine mode are equivalent to pump mode, except for fluid direction that is inversed (suction and discharge) and the rotational speed of the impeller, value calculated in Table 4.

\section{Results}

The numerical results in pump mode are compared with the factory experimental curve, while in turbine mode are compared with theoretical calculations. Table 5 details each simulated point in pump mode, seen in Figure 1. In the comparison, the relative error $E_{r e l}[\%]$ is used to determine the percentage deviation of efficiency and the absolute error $E_{a b s}[\%]$, which is the difference between numerical and manufacturer's efficiency. The maximum relative error is $16.00 \%$ and the absolute error is $7.20 \%$, in point 7 . On the other hand, the minimum relative error is $5.45 \%$, and the absolute error is $3.00 \%$, in point 6 . In the BEP, the relative error is $6.29 \%$, and the absolute error is $3.52 \%$. As the points are analyzed outside the $B E P$, both parameters tend to increase.

Table 5

Simulated points in pump mode

\begin{tabular}{lllllllllll}
\hline \multicolumn{1}{l}{ Manufacturer's curve } & \multicolumn{9}{l}{ Numerical simulation } \\
Point & $\mathrm{H}[\mathrm{m}]$ & $Q\left[\mathrm{~m}^{3} / \mathrm{h}\right]$ & $\eta[\%]$ & $P[\mathrm{~kW}]$ & $\mathrm{H}[\mathrm{m}]$ & $Q\left[\mathrm{~m}^{3} / \mathrm{h}\right]$ & $\eta[\%]$ & $P[\mathrm{~kW}]$ & $E_{\text {rel }}[\%]$ & $E_{a b s}[\%]$ \\
\hline 1 & 23.57 & 6.66 & 30.00 & 1.42 & 24.54 & 6.66 & 34.13 & 1.30 & 13.77 & 4.13 \\
2 & 23.27 & 12.58 & 45.00 & 1.77 & 24.21 & 12.58 & 49.04 & 1.69 & 8.98 & 4.04 \\
3 & 22.93 & 16.02 & 50.00 & 2.00 & 23.94 & 16.02 & 54.40 & 1.91 & 8.81 & 4.40 \\
4 & 21.94 & 21.64 & 55.00 & 2.34 & 22.76 & 21.64 & 58.71 & 2.28 & 6.75 & 3.71 \\
5 (BEP) & 20.71 & 25.49 & 56.00 & 2.56 & 21.44 & 25.49 & 59.52 & 2.49 & 6.29 & 3.52 \\
6 & 18.93 & 29.49 & 55.00 & 2.76 & 19.50 & 29.49 & 58.00 & 2.69 & 5.45 & 3.00 \\
7 & 14.39 & 35.53 & 45.00 & 3.09 & 15.43 & 35.53 & 52.20 & 2.85 & 16.00 & 7.20 \\
\hline
\end{tabular}

Table 6 shows the results obtained in the numerical simulation in turbine mode. In this case, there is convergence from point 2, because a flow rate below $18 \mathrm{~m}^{3} / \mathrm{h}$ and above $60 \mathrm{~m}^{3} / \mathrm{h}$ presents low efficiencies. In the BEP, it is determined that head is $51.65 \mathrm{~m}$, to obtain a maximum efficiency of $50.49 \%$, which represents a relative error of $9.95 \%$ and absolute error of $5.14 \mathrm{~m}$, compared to the head instead of the efficiency. 
Table 6

Simulated points in turbine mode

\begin{tabular}{lllll}
\hline Point & $H[\mathrm{~m}]$ & $Q\left[\mathrm{~m}^{3} / \mathrm{h}\right]$ & $\eta_{t}[\%]$ & $P[\mathrm{~kW}]$ \\
\hline 1 & 8.55 & 6.66 & 0.00 & 0.00 \\
2 & 20.44 & 18.05 & 12.01 & 0.12 \\
3 & 36.93 & 35.53 & 44.38 & 1.58 \\
4 (BEP) & 51.65 & 43.99 & 50.49 & 3.12 \\
5 & 77.61 & 57.77 & 46.91 & 5.71 \\
\hline
\end{tabular}

Finally, Table 7 describes the results respect to BEP, where the relative and absolute error is used for comparison. In pump mode it is compared with the manufacturer's characteristic curve and turbine mode in relation to mathematical modeling.

Table 7

Numerical-experimental comparison of the BEP in both modes

\begin{tabular}{llllllllll}
\hline Mode & Analysis type & $Q\left[\mathrm{~m}^{3} / \mathrm{h}\right]$ & $H[\mathrm{~m}]$ & $\eta[\%]$ & $P[\mathrm{~kW}]$ & $N_{s}$ & $n[\mathrm{rpm}]$ & $E_{\text {rel }}[\%]$ & $E_{a b s}$ \\
\hline Pump & Manufacturer & 25.49 & 20.71 & 56.00 & 2.56 & 12.57 & 1450 & 6.29 & $3.52 \%$ \\
& Numerical & & 21.44 & 59.52 & 2.49 & 12.25 & & & \\
\multirow{2}{*}{ Turbine } & Theorical & 43.99 & 56.79 & - & - & 7.38 & 1382 & 9.95 & $5.14 \mathrm{~m}$ \\
& Numerical & & 51.65 & 50.49 & 3.12 & 7.93 & & & \\
\hline
\end{tabular}

Figure 7 shows the comparison between the manufacturer's characteristic curve and CFD. The head and numerical efficiency curve is above the manufacturer's curve, while the power is below. The trend of the head curve is decreasing, the efficiency is concave downwards and the power is increasing.

Figure 8 shows the numerical characteristic curve in turbine mode. The head and power curve have an increasing trend, while the efficiency is concave downwards, as in the pump mode. Analyzing, if a higher mass flow is entered, the pump could deliver more power, but the efficiency would decrease, so the energy conversion would not be optimal. Therefore, it is advisable to operate the PAT at points near the BEP. For each graph, a perpendicular line is drawn, indicating the BEP region.

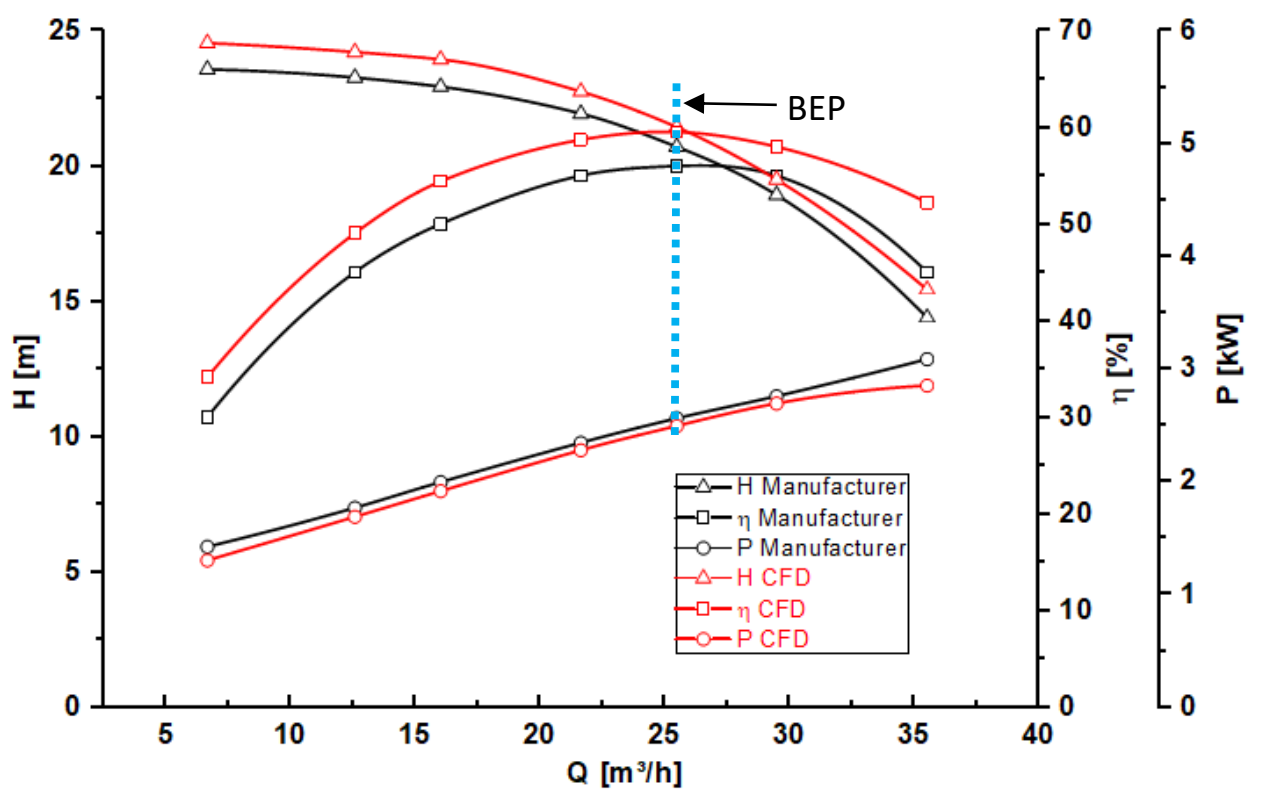

Fig. 7. Experimental and numerical comparison of the characteristic curve 


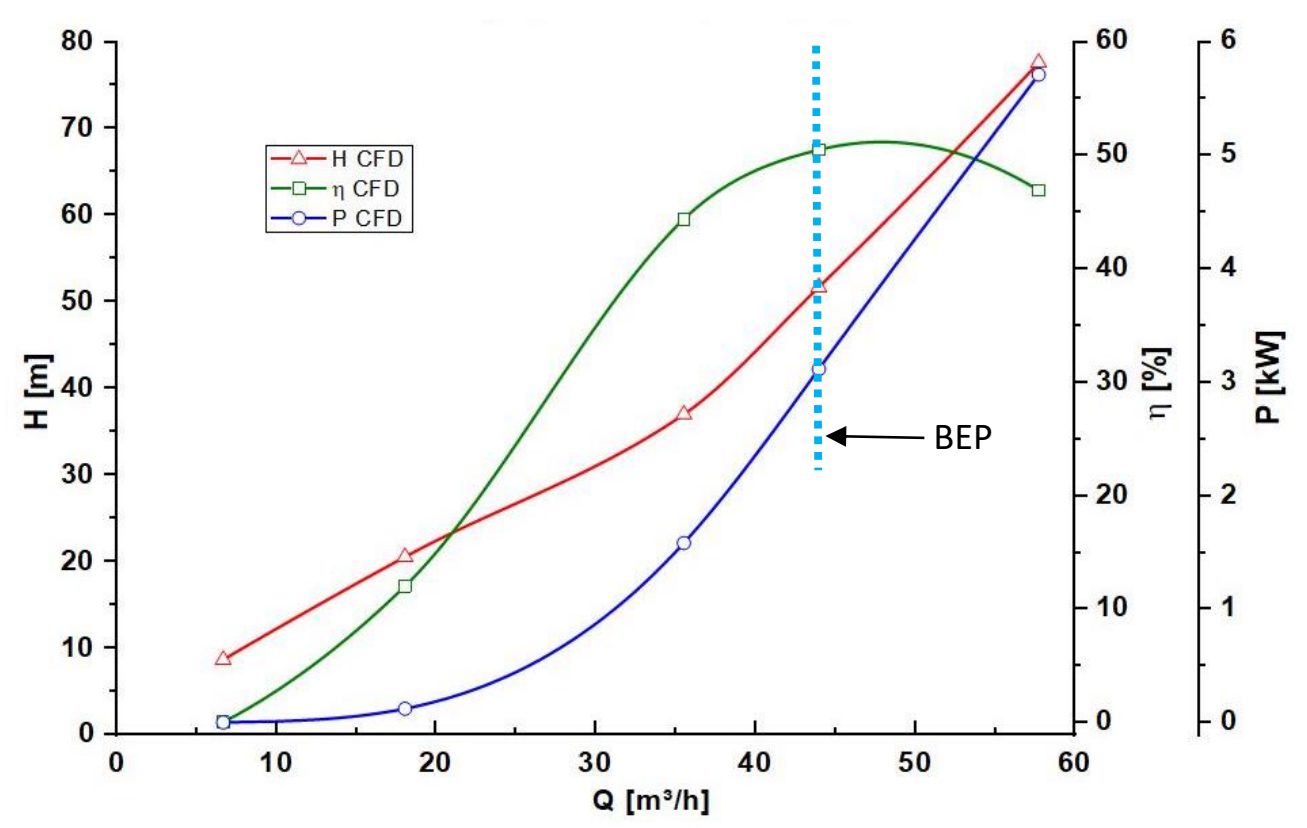

Fig. 8. Characteristic curve in turbine mode

Figure 9 shows the contour of pressure and speed of the simulations performed. (a) and (b) show the contours of pressure and velocity in pump mode, while (c) and (d) in turbine mode, respectively. The black arrows detail the direction of the fluid. In (a) you can see that in suction the pressure decreases to a value close to $-377 \mathrm{kPa}$ just as the fluid enters the impeller, and gradually increases in the volute up to $512 \mathrm{kPa}$. The negative pressure indicates the suction effect exerted by the impeller towards the fluid, as well as possible cavitation effects, given the reference pressure. In (b) the opposite occurs. The fluid is suctioned at a speed between 3-5 m/s. When it enters the impeller, the speed increases suddenly up to $17 \mathrm{~m} / \mathrm{s}$, due to the rotation. When the fluid enters the volute, the speed decreases, being inverse to the pressure. In (c) and (d) something similar occurs, where the suction records a maximum pressure of $308 \mathrm{kPa}$ and decreases as it passes through the impeller to $40 \mathrm{kPa}$, because the fluid loses energy as it hits the blades. On the other hand, the fluid enters the volute with a velocity close to $9 \mathrm{~m} / \mathrm{s}$, increasing as it hits the blades, reaching a maximum of $24 \mathrm{~m} / \mathrm{s}$. Subsequently, the speed decreases as it passes through the impeller because the kinetic energy of the fluid is transferred to the impeller. To the right of each contour, the view of the blade region is shown. 

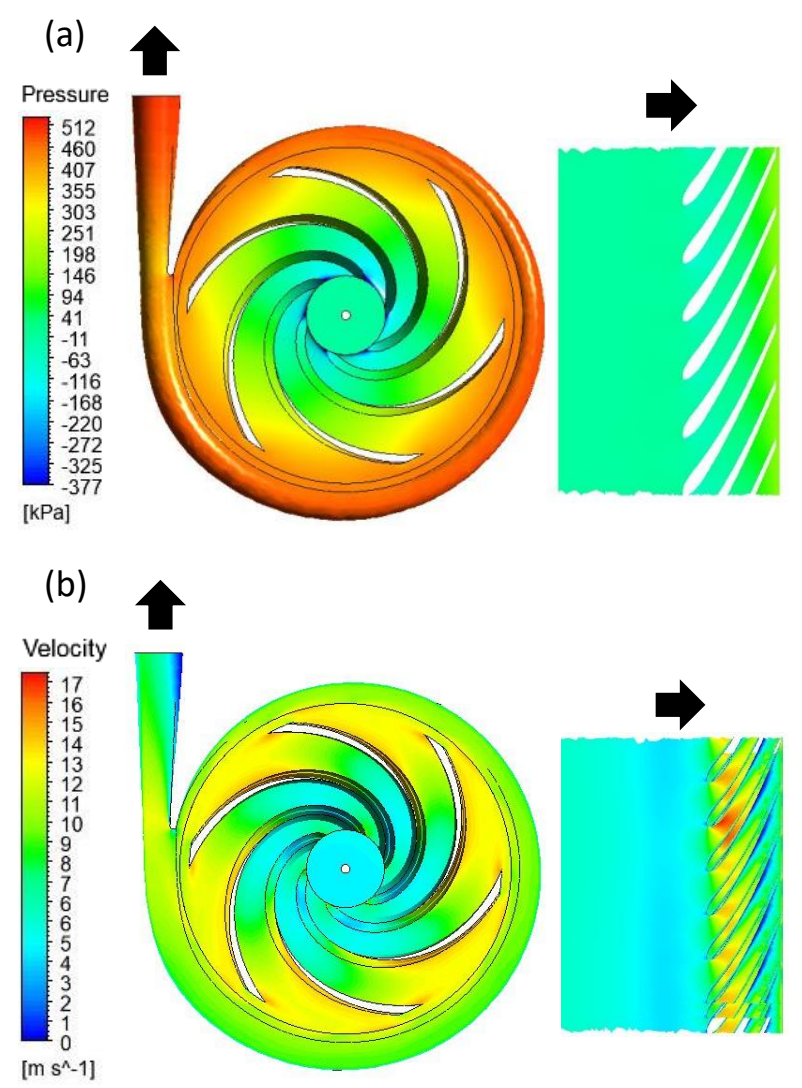
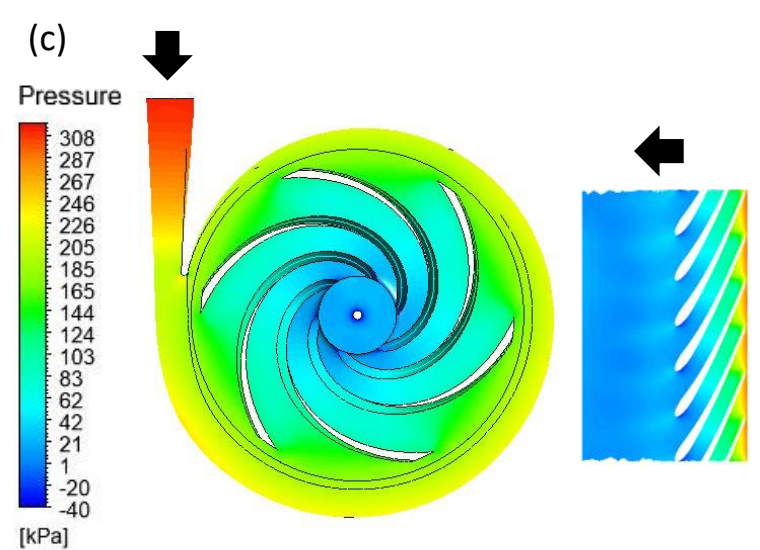

(d)

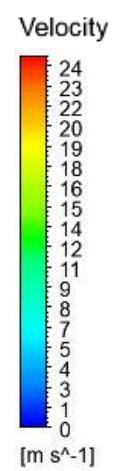

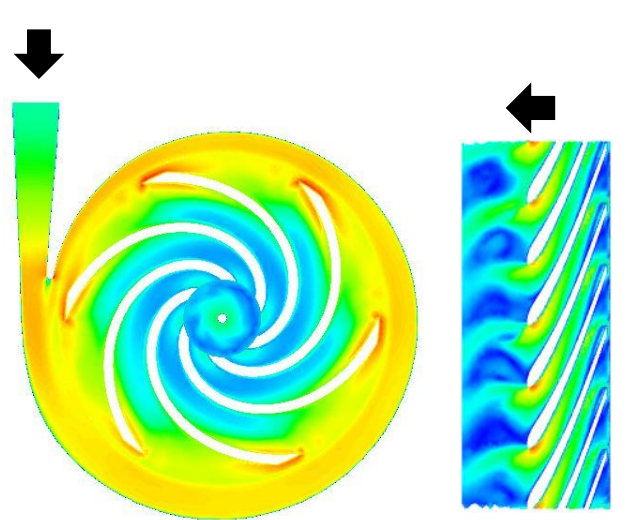

Fig. 9. (a), (b) Pressure and velocity contours in pump mode and (c), (d) turbine mode

Finally, Figure 10 validates the operation point of commercial PAT in the selection graph, respect to data recorded in Table 7 [10]. The scale on the axes is logarithmic and non-linear. The position is in accordance with the results obtained. However, it is noted that the power should be approximated to $6 \mathrm{~kW}$ instead of $3.12 \mathrm{~kW}$. This is due to the energy losses concerning transmission and efficiency in the turbomachine.

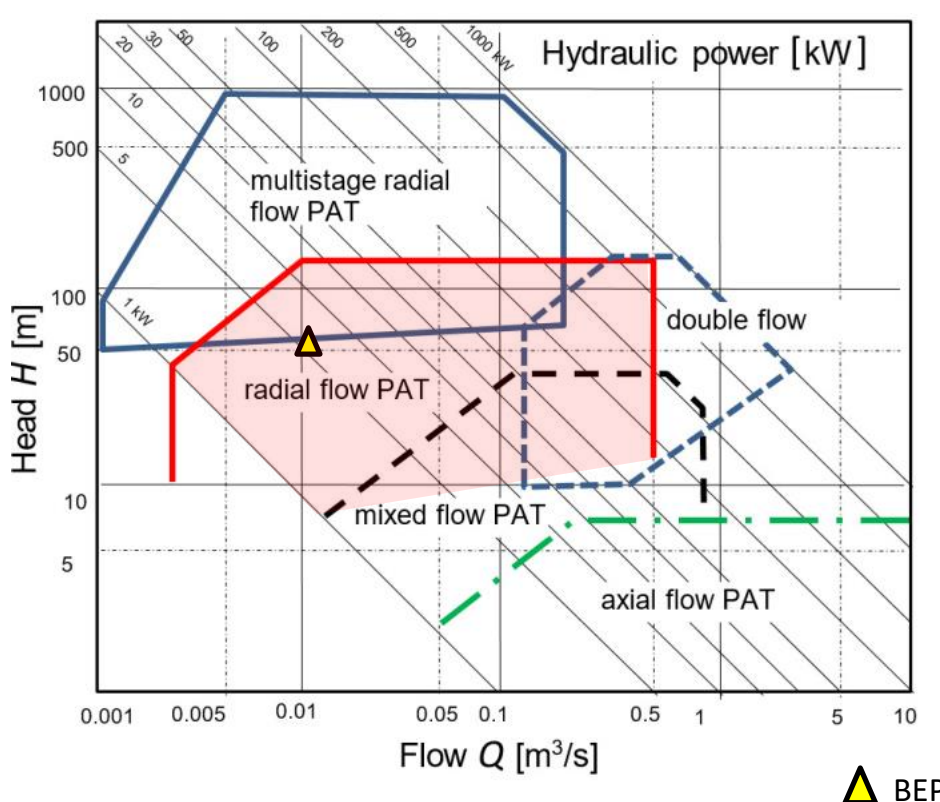

Fig. 10. Point of PAT operation 


\section{Conclusions}

Through computer simulations, a methodology applicable to centrifugal radial flow pump operating as turbine is developed, to support non-interconnected areas in the selection of this type of turbomachine for their own hydroelectric generation. By validating the fluid dynamic simulation in pump and turbine mode, a relative error of less than $10 \%$ is obtained between the characteristic curves. The proposed methodology is easy to replicate for a radial flow pump and influences to reduce the costs of experimental tests. In addition, the following was reached

i. The geometric computer model of the pump control volumes is obtained, where they are parameterized respect to information provided by the manufacturer.

ii. The control volume is discretized in finite elements, obtaining aspects such as the aspect ratio below 13 , expansion below 18 and orthogonal quality greater than 0.18 . Therefore, mesh is taken with the minimum metrics to export to Ansys-CFX.

iii. Comparison is made in relation to the manufacturer's characteristic curve. A relative error of $6.29 \%$ is obtained, validating the numerical simulation.

iv. The characteristic curve of the pump operating as a turbine is estimated. A relative error of $9.95 \%$ is obtained respect to theoretical head, less than $20 \%$ inquired into the state of the art.

v. To decrease the relative error between the experimental and the numerical it is necessary to use inflation layers to be able to capture the physical phenomena close to the wall

\section{Acknowledgement}

The authors would like to thank the Advanced Materials and Energy research group (MATyER), especially the research line of Advanced Computing and Digital Design and Manufacturing Processes (SeCADD-ProM) and the system department of the Metropolitan Technological Institute (ITM), for allowing the use of the computer equipment and licenses of the Ansys ${ }^{\circledR}$ software to perform the simulations.

\section{References}

[1] Day, John W., Christopher F. D'Elia, Adrian RH Wiegman, Jeffrey S. Rutherford, Charles AS Hall, Robert R. Lane, and David E. Dismukes. "The energy pillars of society: Perverse interactions of human resource use, the economy, and environmental degradation." Biophysical Economics and Resource Quality 3, no. 1 (2018): 1-16. https://doi.org/10.1007/s41247-018-0035-6

[2] Pinkse, Jonatan, and Koen Groot. "Sustainable entrepreneurship and corporate political activity: Overcoming market barriers in the clean energy sector." Entrepreneurship Theory and Practice 39, no. 3 (2015): 633-654. https://doi.org/10.1111/etap.12055

[3] United Nations. "Energy." United Nations Department of Economic and Social Affairs Sustainable Development. Accessed October 17, 2020. https://sdgs.un.org/goals/goal7.

[4] Dincer, Ibrahim, and Canan Acar. "A review on clean energy solutions for better sustainability." International Journal of Energy Research 39, no. 5 (2015): 585-606. https://doi.org/10.1002/er.3329

[5] IRENA. "Renewable Power Generation Costs in 2018." International Renewable Energy Agency, Abu Dhabi (2019).

[6] REN21 Secretariat. "Renewables 2019 Global Status Report." REN21 Renewables Now, Paris, France (2019).

[7] IHA Central Office. "Hydropower status report." International Hydropower Association, London, UK (2018).

[8] Acolgen. "Mapa de Generación Eléctrica en Colombia." Colombian Association of Electric Power Generators, Acolgen, April 25, 2020. https://www.acolgen.org.co/mapa-generacion/.

[9] UPME Gov. "Mapas." Unidad de Planeacion Minero Energetica. Accessed April 25, 2020. http://sig.simec.gov.co/GeoPortal/Mapas/Mapas.

[10] Chapallaz, Jean-Marc, Peter Eichenberger, and Gerhard Fischer. Manual on pumps used as turbines. Vieweg, Braunschweig, Germany, 1992.

[11] Vargas, Fabio Emiro Sierra, Adriana Fernanda Sierra Alarcón, and Carlos Alberto Guerrero Fajardo. "Pequeñas y microcentrales hidroeléctricas: alternativa real de generación eléctrica." Informador Técnico 75 (2011): 73-85. https://doi.org/10.23850/22565035.22 
[12] Binama, Maxime, Wen-Tao Su, Xiao-Bin Li, Feng-Chen Li, Xian-Zhu Wei, and Shi An. "Investigation on pump as turbine (PAT) technical aspects for micro hydropower schemes: A state-of-the-art review." Renewable and Sustainable Energy Reviews 79 (2017): 148-179. https://doi.org/10.1016/j.rser.2017.04.071

[13] Motwani, K. H., S. V. Jain, and R. N. Patel. "Cost analysis of pump as turbine for pico hydropower plants-a case study." Procedia Engineering 51 (2013): 721-726. https://doi.org/10.1016/j.proeng.2013.01.103

[14] Kusakana, Kanzumba. "A survey of innovative technologies increasing the viability of micro-hydropower as a cost effective rural electrification option in South Africa." Renewable and Sustainable Energy Reviews 37 (2014): 370 379. https://doi.org/10.1016/i.rser.2014.05.026

[15] Williams, A. A. "Pumps as turbines for low cost micro hydro power." Renewable Energy 9, no. 1-4 (1996): $1227-$ 1234. https://doi.org/10.1016/0960-1481(96)88498-9

[16] Krenn, Jürgen, Helmut Keck, and Manfred Sallaberger. "Small and mid-size pump-turbines with variable speed." Energy and Power Engineering 5, no. 2 (2013): 48-54. https://doi.org/10.4236/epe.2013.52A007

[17] Shabani, Masoume, and Javad Mahmoudimehr. "Techno-economic role of PV tracking technology in a hybrid PVhydroelectric standalone power system." Applied Energy $212 \quad$ (2018): 84-108. https://doi.org/10.1016/j.apenergy.2017.12.030

[18] Nyeche, E. N., and E. O. Diemuodeke. "Modelling and optimisation of a hybrid PV-wind turbine-pumped hydro storage energy system for mini-grid application in coastline communities." Journal of Cleaner Production 250 (2020): 119578. https://doi.org/10.1016/j.jclepro.2019.119578

[19] Yang, Sun-Sheng, Shahram Derakhshan, and Fan-Yu Kong. "Theoretical, numerical and experimental prediction of pump as turbine performance." Renewable Energy $48 \quad$ (2012): $507-513$. https://doi.org/10.1016/i.renene.2012.06.002

[20] Suhissa. "Principales Aplicaciones De Las Bombas Centrífugas." Suhissa. Accessed October 27, 2019. https://suhissa.com.mx/principales-aplicaciones-de-las-bombas-centrifugas/.

[21] Huang, Si, Guangqi Qiu, Xianghui Su, and Guowei Ou. "Flow performance analysis on shutoff condition in centrifugal pump based on CFD simulation." In 2014 ISFMFE-6th International Symposium on Fluid Machinery and Fluid Engineering, pp. 1-5. IET, 2014. https://doi.org/10.1049/cp.2014.1142

[22] Patel, Kiran, and N. Ramakrishnan. "CFD analysis of mixed flow pump." In International ANSYS Conference Proceedings. 2006.

[23] Qian, Zhongdong, Fan Wang, Zhiwei Guo, and Jie Lu. "Performance evaluation of an axial-flow pump with adjustable guide vanes in turbine mode." Renewable Energy 99 (2016): 1146-1152. https://doi.org/10.1016/j.renene.2016.08.020

[24] Graciano-Uribe, Jonathan, Jorge Sierra, and Edwar Torres-López. "Instabilities and influence of geometric parameters on the efficiency of a pump operated as a turbine for micro hydro power generation: A review." Journal of Sustainable Development of Energy, Water and Environment Systems (2020). https://doi.org/10.13044/i.sdewes.d8.0321

[25] Barbarelli, S., M. Amelio, and G. Florio. "Experimental activity at test rig validating correlations to select pumps running as turbines in microhydro plants." Energy Conversion and Management 149 (2017): $781-797$. https://doi.org/10.1016/j.enconman.2017.03.013

[26] Fernández, J., R. Barrio, E. Blanco, J. L. Parrondo, and A. Marcos. "Numerical investigation of a centrifugal pump running in reverse mode." Proceedings of the Institution of Mechanical Engineers, Part A: Journal of Power and Energy 224, no. 3 (2010): 373-381. https://doi.org/10.1243/09576509JPE757

[27] Renzi, Massimiliano, Pavel Rudolf, David Štefan, Alessandra Nigro, and Mosè Rossi. "Installation of an axial Pumpas-Turbine (PaT) in a wastewater sewer of an oil refinery: A case study." Applied Energy 250 (2019): 665-676. https://doi.org/10.1016/i.apenergy.2019.05.052

[28] Delgado, J., J. P. Ferreira, D. I. C. Covas, and F. Avellan. "Variable speed operation of centrifugal pumps running as turbines. Experimental investigation." Renewable Energy $142 \quad$ (2019): $437-450$. https://doi.org/10.1016/i.renene.2019.04.067

[29] Rawal, Sonia, and J. T. Kshirsagar. "Numerical simulation on a pump operating in a turbine mode." In Proceedings of The 23rd International Pump Users Symposium. Texas A\&M University. Turbomachinery Laboratories, pp. 21-27. 2007.

[30] Bozorgi, A., A. Riasi, and A. Nourbakhsh. "Investigation of effects of changing blade position and size reduction on performance of axial pump used as turbine." In Applied Mechanics and Materials, vol. 110, pp. 2933-2939. Trans Tech Publications Ltd, 2012. https://doi.org/10.4028/www.scientific.net/AMM.110-116.2933

[31] Han, Yadong, and Lei Tan. "Dynamic mode decomposition and reconstruction of tip leakage vortex in a mixed flow pump as turbine at pump mode." Renewable Energy 155 (2020): $725-734$. https://doi.org/10.1016/i.renene.2020.03.142 
[32] Stefanizzi, Michele, Tommaso Capurso, Gabriella Balacco, Mario Binetti, Marco Torresi, and Sergio Mario Camporeale. "Pump as turbine for throttling energy recovery in water distribution networks." In AIP Conference Proceedings, vol. 2191, no. 1, p. 020142. AIP Publishing LLC, 2019. https://doi.org/10.1063/1.5138875

[33] Zhang, Wenwu, Zhenmu Chen, Baoshan Zhu, and Fei Zhang. "Pressure fluctuation and flow instability in S-shaped region of a reversible pump-turbine." Renewable Energy $154 \quad$ (2020): 826-840. https://doi.org/10.1016/i.renene.2020.03.069

[34] Widmer, Christian, Thomas Staubli, and Nathan Ledergerber. "Unstable characteristics and rotating stall in turbine brake operation of pump-turbines." Journal of Fluids Engineering 133, no. 4 (2011): 041101. https://doi.org/10.1115/1.4003874

[35] KSB. "MegaCPK." MegaCPK - Bomba de voluta partida radialmente con impulsor radial o impulsor D. Accessed May 21, 2021. https://www.ksb.com/es-es/lc/productos/bomba/bomba-instalada-en-seco/megacpk/M48A.

[36] KSB. "Bomba Química Normalizada MegaCPK." Bombas centrífugas con cierre del eje, Bombas químicas normalizadas. Accessed March $\quad$ 15, 2020. https://shop.ksb.com/ims docs/00/00215A9B0E3D1EDA959DB030E38BACB9.pdf.

[37] Yang, Sun-Sheng, Fan-Yu Kong, Hao Chen, and Xiang-Hui Su. "Effects of blade wrap angle influencing a pump as turbine." Journal of Fluids Engineering 134, no. 6 (2012). https://doi.org/10.1115/1.4006677

[38] Sun-Sheng, Yang, Punit Singh, and Hui Zhang. "Flow investigations of reverse running volute pumps with backward vanes in comparison to forward type turbine vanes." Proceedings of the Institution of Mechanical Engineers, Part A: Journal of Power and Energy 233, no. 1 (2019): 111-131. https://doi.org/10.1177/0957650918768354

[39] Liu, Ming, Lei Tan, and Shuliang Cao. "Theoretical model of energy performance prediction and BEP determination for centrifugal pump as turbine." Energy 172 (2019): 712-732. https://doi.org/10.1016/i.energy.2019.01.162

[40] ANSYS. ANSYS CFX-Solver Modeling Guide. Release 14.0. ANSYS, Inc., (2011).

[41] Yoon, Gil Ho. "Topology optimization method with finite elements based on the k- $\varepsilon$ turbulence model." Computer Methods in Applied Mechanics and Engineering 361 (2020): 112784. https://doi.org/10.1016/i.cma.2019.112784

[42] Ghorani, Mohammad Mahdi, Mohammad Hadi Sotoude Haghighi, Ali Maleki, and Alireza Riasi. "A numerical study on mechanisms of energy dissipation in a pump as turbine (PAT) using entropy generation theory." Renewable Energy 162 (2020): 1036-1053. https://doi.org/10.1016/i.renene.2020.08.102

[43] Yusuf, Siti Nurul Akmal, Yutaka Asako, Nor Azwadi Che Sidik, Saiful Bahri Mohamed, and Wan Mohd Arif Aziz Japar. "A Short Review on RANS Turbulence Models." CFD Letters 12, no. 11 (2020): 83-96. https://doi.org/10.37934/cfdl.12.11.8396

[44] Bardina, J. E., P. G. Huang, and T. J. Coakley. Turbulence modeling validation, testing. and development, technical report, NASA, US. NASA Technical Memorandum, 1997. https://doi.org/10.2514/6.1997-2121

[45] Ismail, Mohd Azlan, Al Khalid Othman, and Hushairi Zen. "Numerical simulation on end suction centrifugal pump running in inverse flow for microhydro applications." In Applied Mechanics and Materials, vol. 773, pp. 358-362. Trans Tech Publications Ltd, 2015. https://doi.org/10.4028/www.scientific.net/AMM.773-774.358

[46] Mott, Robert L. Mecanica de Fluidos 6/e. Pearson educación, 2006.

[47] Lorusso, Michele, Tommaso Capurso, M. Torresi, B. Fortunato, F. Fornarelli, S. M. Camporeale, and Rosario Monteriso. "Efficient CFD evaluation of the NPSH for centrifugal pumps." Energy Procedia 126 (2017): 778-785. https://doi.org/10.1016/j.egypro.2017.08.262

[48] Mataix, Claudio. Turbomáquinas hidráulicas. Editorial ICAI, Madrid (1975).

[49] Mataix, Claudio. Mecánica de fluidos y máquinas hidráulicas. No. 620.106 M38 2012. Harla, 1982.

[50] Rossi, Mosè, Alessandra Nigro, Giuseppe Roberto Pisaturo, and Massimiliano Renzi. "Technical and economic analysis of Pumps-as-Turbines (PaTs) used in an Italian Water Distribution Network (WDN) for electrical energy production." Energy Procedia 158 (2019): 117-122. https://doi.org/10.1016/i.egypro.2019.01.055

[51] Barbarelli, Silvio, Mario Amelio, and Gaetano Florio. "Using a statistical-numerical procedure for the selection of pumps running as turbines to be applied in water pipelines: Study cases." Journal of Sustainable Development of Energy, Water and Environment Systems 6, no. 2 (2018): 323-340. https://doi.org/10.13044/i.sdewes.d5.0181

[52] Tan, Xu, and Abraham Engeda. "Performance of centrifugal pumps running in reverse as turbine: Part II-systematic specific speed and specific diameter based performance prediction." Renewable Energy 99 (2016): 188-197. https://doi.org/10.1016/i.renene.2016.06.052

[53] Singh, Punit, and Franz Nestmann. "An optimization routine on a prediction and selection model for the turbine operation of centrifugal pumps." Experimental Thermal and Fluid Science 34, no. 2 (2010): 152-164. https://doi.org/10.1016/i.expthermflusci.2009.10.004

[54] Derakhshan, Shahram, and Ahmad Nourbakhsh. "Experimental study of characteristic curves of centrifugal pumps working as turbines in different specific speeds." Experimental Thermal and Fluid Science 32, no. 3 (2008): 800-807. https://doi.org/10.1016/i.expthermflusci.2007.10.004 
[55] Carravetta, Armando, Shahram Derakhshan Houreh, and Helena M. Ramos. Pumps as Turbines: Fundamentals and Applications. Springer, 2018. https://doi.org/10.1007/978-3-319-67507-7

[56] Smith, Michael. "Useful information on specific speed and suction specific speed." Michael Smith Engineers, Ltd. Accessed October 12, 2020. https://www.michael-smith-engineers.co.uk/resources/useful-info/specific-speed.

[57] Stefanizzi, M., M. Torresi, B. Fortunato, and S. M. Camporeale. "Experimental investigation and performance prediction modeling of a single stage centrifugal pump operating as turbine." Energy Procedia 126 (2017): 589-596. https://doi.org/10.1016/i.egypro.2017.08.218

[58] Neutrium. "Pump Specific Speed." Native https://neutrium.net/equipment/pump-specific-speed/.

Dynamics.

Accessed

August

20,

2013. 